\title{
LexiPal: Design, Implementation and Evaluation of Gamification on Learning Application for Dyslexia
}

\author{
Muhamad Risqi Utama Saputra \\ Research and Development Division, \\ Nextln Indonesia \\ Yogyakarta, Indonesia
}

\begin{abstract}
As a specific learning disability, dyslexia is not curable, yet manageable. Dyslexia management is usually conducted as extra learning program using multisensory method which is called remediation. However, some studies indicate that students with dyslexia have lower motivation in learning than students without dyslexia. This research design a learning model for dyslexic children, termed LexiPal, using gamification approach as motivational affordances. The proposed model incorporates 7 game elements: story/theme, clear goals, levels, points, rewards, feedback, and achievements/badges, to improve desired psychological outcomes, namely engagement, enjoyment, and motivation. The developed application, based on Windows Presentation Foundation (WPF) technology, was evaluated to dyslexic children $(n=40)$ through 2 steps, qualitative and quantitative step. Qualitative step using observation was intended to observe the engagement of dyslexic children when using the application. Quantitative step using simple Q\&A adopted from questionnaire was purposed to confirm whether dyslexic children feel enjoyment and motivated when and after using the application.
\end{abstract}

\section{Keywords}

Gamification, learning application, dyslexia, psychological outcomes, engagement, enjoyment, motivation.

\section{INTRODUCTION}

Dyslexia is a specific learning disability characterized by difficulties with accurate and/or fluent word recognition, poor spelling, and poor decoding abilities [1]. It is a literacy-based learning difficulty that affects persons who have at least average intelligence (IQ > 90) and whose reading problems are not due to extraneous factors, e.g. sensory acuity deficits or socio-economic backgrounds. Most experts believe that dyslexia is familial and heritable [2]. It can be found in approximately $10 \%$ to $15 \%$ of school age children despite different ethnics and backgrounds [3]. Moreover, based on International Dyslexia Association (IDA), many more persons (about $15 \%$ to $20 \%$ of the whole population) may have some symptoms of dyslexia including slow reading, poor spelling, poor writing, or mixing up similar words [1].

Eventhough dyslexia is not curable, dyslexic could overcome their problem if they are treated correctly. These include intervention and remediation program using multisensory approach in all of reading aspects such as phonemic awareness, phonics, reading fluency, vocabulary, and reading comprehension strategies [4]. However, remediation usually take additional time beside of daily learning activities in school. Burdened by their difficulty and compulsion to spend extra time undertaking types of activities that they typically struggle with, many dyslexic become demotivated and have low levels of self-esteem [5]. A study shows that students with dyslexia have lower motivation than students without dyslexia in reading and other aspects of learning [6]. Thus, some researchers suggest to apply motivational teaching strategies in order to boost dyslexic motivation [5].

In regards of motivational strategy, it is commonly known in context of e-learning that giving points, scores, or rewards to student that successfully finish a task can increase motivation and engagement in learning process [7] [8] [9]. The process to use game design elements, such as points or rewards, in nongame contexts is called "gamification" [10]. Gamification is widely used in education/learning area [7], yet its implementation and its effect on the learning process of dyslexic student has not been addressed profoundly. Some researchers develop gamified learning application for dyslexia [11] [12] [13] [14], but they did not specify which game elements they utilize, nor investigate its effect. Malekian and Askari investigates the effect of multi-sensory games on children with dyslexia, yet they focus on the impact of multisensory approach, not the gamified aspect [15]. Current study by Daniel Gooch et al. explore the use of gamification platform in order to foster the motivation of students with dyslexia [5]. Their research used only one game element, namely badges, which is attractive enough to keep dyslexic student engaged with the learning platform. However, a badge is usually given at particular time or specific milestone/achievement. It means, there are period of time when dyslexic student do not get any motivational affordances. In addition, only the achiever one who will get the badge. Some students who never reach the target can lack motivation gradually, whereas continuous encouragement is important for dyslexic with low self-estem. Thus, it need much more game elements to keep dyslexic motivated. Moreover, their result concerns on the best practice of effective teaching using gamified application, not the effect of gamification.

This research works on the implementation and the effect of gamification approach towards dyslexic learning process. The project, termed LexiPal, consists of designing learning model using gamification elements, implementing the design in software application, and measuring the effectiveness of the design toward desired psychological outcomes. The aims of LexiPal are to close the gap of previous researches by (1) incorporating more game elements in an application, (2) designing the sequence of game elements that will be delivered at each stage/page of the application, and (3) evaluating the outcomes which not only limited to motivation, but also engagement and enjoyment. Finally, this paper is organized as follows: section II describes related work, section III briefs the gamification theory, section IV shows the design and the implementation of LexiPal, section V discuss the evaluation, and last section concludes the paper. 


\section{RELATED WORK}

Works in area of learning application for dyslexic children have been done by a lot of researchers throughout the world. The application ranges from desktop, mobile, and web-based application. Most of them implements multisensory teaching approach. Daud and Abas [16] developed "Dyslexia Baca", a mobile application that help dyslexic children to recognize and distinguish letter $\mathrm{p}, \mathrm{q}, \mathrm{b}, \mathrm{d}, \mathrm{m}$, and $\mathrm{w}$. The application is developed in Malay language, based on multisensory approach, and intended to assist alphabet recognition thus dyslexic children can learn and recall the information easily. Heuristic evaluation of this application shows that the application is well designed in aspects of content, approach, and multimedia elements with mean score of 4.4 to 4.8 . Skiada, et al. [17] also created a mobile application named "EasyLexia" which hopefully could foster learning and improve some of dyslexic fundamental skills in English language. Preliminary evaluation of this app with 5 dyslexic children shows promising results in such contexts as the students showed progress in performance over a short period of time. S. Purkayastha, et al. [18] used Orton-Gillingham (OG) instructional approach to develop an application called "Dyscover". "Dyscover" is HTML5-based application that take into account most aspects of modern technologies in ICT, such as touchscreens, accelerometers, gyroscopes, voice recognition, sound reproduction, etc., and correlate it with implementation of multisensory approach. The application also personalize the implementation of OG using Gardner's theory of multiple intelligences.

Some studies incorporate phonics reading technique in their application. Created in Malay language, Ahmad, et al. [19] developed "Bijak Membaca", an application for dyslexic children which applies Phonic Reading Technique and multisensory approach with interactive multimedia, such as text, graphics, video, and animation. Evaluated using Heuristic approach, this application is considered success in integrating all of learning strategies mentioned before. "JollyMate" was developed to implement phonics technique as well [20]. The application was designed as digital notepad/school notebook. It was utilized jolly phonics system to teach letter sound and letter formation. It also adds handwriting character recognition to teach writing.

Other recent works on this area adopt game concept in their application. Dyslexia Activity System (DAS) uses gaming techniques and multisensory approach to help capture dyslexic attention and motivates them to learn through a fun environment [11]. DAS was also developed to help identify where dyslexic mistakes in reading, writing, and arithmetic. Rello [13] designed a game called "Dyseggxia" that contains word exercises in Spanish Language. The content of the application combines linguistic, pedagogical criteria, and corpus analysis. The application is available in Android and iOS. Di Tore [14] developed "Madrigale" as educational action games that promotes phonological training and visuospatial attention in dyslexic. Gooch [5] explore the use of gamification in "ClassDojo" platform toward the student motivation. Their research uses badges as gamification element and their result concerns on the best practice of effective teaching using gamified application.

All of previously mentioned researches do not mention about the implementation of gamification approach in their research, except ClassDojo. However, ClassDojo only uses one game element and their result focuses on the best practice of effective teaching using gamified application. Despite some of them state that they create a fun and exciting game, they do not clearly state the aspect of gamification concept that they used, nor evaluate its implementation.

\section{GAMIFICATION THEORY 3.1 Brief History}

"Gamification" term has been used widely since the second half of 2010 by the game industry and the game studies community [10], yet the first recorded term appeared around 2002 on Nick Pelling's article [21]. From year to year, other similar terms like playful design, applied gaming, or productivity game are being used. As a result, these terms become contested term among industries and communities. However, gamification manages to rise and become the most prominent term because of the current cultural momentum of video games. Foursquare and Nike+ are examples of company which are considered very successful on implementing gamification on their mass market products [22].

In current industry, the notion of gamification exchanges between two concepts. The first one defines gamification as the rising adoption, institutionalization, and ubiquity of games technology in our daily life. On the other hand, others agree that gamification is the idea of inserting game elements to non-game products and services in order to make it more enjoyable and more engaging [10]. Nevertheless, the last point of view is more noted and widely used in educational technology community.

\subsection{Conceptual Definition}

Gamification is defined as using elements of game design in non-game contexts, products, and services to motivate desired behaviors [22]. Non-game contexts refer to particular field such as commerce, education/learning, health/exercise, intraorganizational systems, sharing, sustainable consumption, work, innovation/ideation, and data gathering [7]. The "motivate desired behaviors" part is important because the main purpose of gamification should be invoking the same psychological experiences as games usually do. Game elements, like levels and points, were already incorporated into stock exchange dashboard, decision support systems, loyalty programs, and other system, however it was not considered as gamification because it did not provide gameful experiences [23]. Furthermore, based on [7], gamification can be divided into three main parts: the implemented motivational affordances (game elements), psychological outcomes, and further behavioral outcomes. This asserts the notion that the use of game elements alone is not enough to be considered as gamification. There must be desired psychological and behavioural outcomes behind gamification adoption.

\subsection{Game Elements and Psychological Outcomes}

There are several motivational affordances which are represented as game elements namely: points, leaderboards, achievements/badges, levels, story/theme, clear goals, feedback, rewards, progress, and challenge. From all of mentioned affordances, the most favourites are points, leaderboards, and badges [7]. These game elements are included in non-game context to yield desired psychological outcomes. These psychological outcomes are manifested as engagement, motivation, and enjoyment [7] [24]. Engagement is described as having two components: (1) behavioral, such as effort and participation, and (2) emotional, such as interest and positive attitude about learning [25]. Motivation is divided into two types namely intrinsic and extrinsic. Intrinsic motivation means student engage with learning material as 
they are inherently interesting and enjoyable, while extrinsic motivation refers to student engaging in actions because they lead to separable external outcomes like grade or prize [26]. Rewards based on game elements is clearly part of extrinsic motivation. Then, enjoyment means the extent to which the activity of using an application is perceived to be personally enjoyable in its own right aside from the instrumental value of technology. Enjoyment is also related to ease of use [27].

\section{DESIGN AND IMPLEMENTATION 4.1 Design of Learning Model}

Many studies investigated the significant improvement of student's motivation, interest, and participation using gamified application as learning tools [15]. While dyslexic children may have issues with motivation [5], the use of gamification approach becomes importance as motivational affordances. The aim is clear, that is minimizing dyslexic failure experiences [28] and increasing their interest/engagement and enjoyment in learning certain subject.

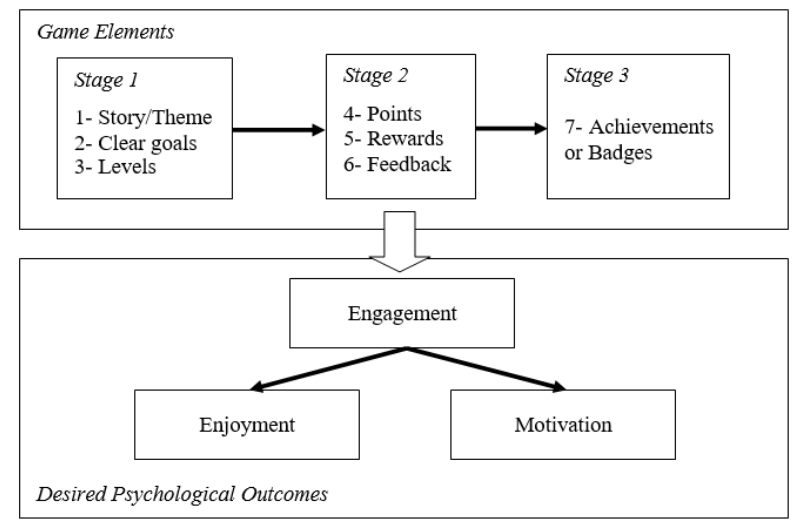

Fig 1: The proposed gamification learning model for dyslexic children

This research designs learning model for dyslexic children by including gamification elements in LexiPal. The learning model was created by selecting 7 prospective game elements and cluster it into several groups that match 3 considerations: the need of dyslexic children, desired psychological outcomes, and the software requirement. Figure 1 demonstrates the proposed gamification learning model for dyslexic children. The game elements involved are story/theme, clear goals, levels, points, rewards, feedback, and achievements/badges. These game elements are grouped into 3 stages which each of it can be implemented as different learning step or different page in a software application. These stages also indicate the order of game elements that should be delivered to the children as they are starting the learning process. For instance, story/theme in Stage 1 means the story behind the learning media should be told first by their teacher or in software perspective, it should be displayed previously before other game elements. Every game element in each stage conforms the same rule. Eventually, these game elements are intended to produce specific psychological outcomes. The first goal is engagement, which means interest/participation in using the application. After the first objective is achieved, the next goals are enjoyment or "fun" experience and motivation to parcipate in the learning process again.

Stage 1 consists of story/theme, clear goals, and levels (difficulty). These 3 information have to be given first as dyslexic children should understand the goals of learning, the story behind it, and the difficulty level they want to play before they start to use the application. By delivering these information at early stage, the purpose is to attract dyslexic attention and make them interest with the presented subject. Every game elements contributes in producing specific psychological outcomes. Story/theme aims for engagement and enjoyment. Interesting story can draw dyslexic interest toward the subject and make them enjoy the learning process, while the absence of story could make them bored. Combined by clear objective, it can engage dyslexic to reach the goals. Finally, difficulty levels is purposed to increase motivation because dyslexic children are encouraged to finish all of available levels.

Stage 2, especially points and rewards, is usually delivered after dyslexic finish one round of game except the feedback that can be given promptly after an event happens. Points and reward are designed for providing continuous encouragement and motivation along the learning process. For every small progress, a point/reward will be given to them. The feedback should be set to give positive respond, either dyslexic got good score or bad score, thus minimizing their failure experiences and encouraging them to learn more. Finally, after achieving some goals, a badge is given in Stage 3 to boost their spirit and motivate them to achieve more.

\subsection{Implementation}

LexiPal was developed on top of Windows platform using Windows Presentation Foundation (WPF) technology in order to create entertaining gamified learning process. WPF can provides smooth animation and excellent graphics for a desktop application because every content is rendered on Graphical Processing Unit (GPU) [29], thus it supports gamification implementation very well. Then, in order to save all of user data and playing records, LexiPal utilizes SQL Server Compact Edition (CE) database.

The content of the application is implemented in Indonesian language and follows its learn-to-read steps. It is adapted from [28] which consists of 12 categories i.e. (1) shape and patterns, (2) similarities, differences, and comparison, (3) short-term memories, (4) object association, (5) direction, (6) sequence of activities, (7) understanding places, (8) concept of time, (9) functional skills, (10) alphabets, (11) syllables and words, and (12) simple sentences. Each category consists of several learning media and it is sorted from the easiest one to the most difficult one as seen in Figure 2. The left part of Figure 2 is an example of some learning media in alphabets category. The learning media in alphabets category is sorted based on learning reading steps in Indonesian language. It starts from learning vocal, learning consonant, distinguishing each phoneme, writing letter, to some gamified exercises about differentiating similar words and its sound. These sequences are indication of adaptation of leveling concept in gamification. Beside the implementation of leveling in a category, leveling is also implemented in a learning media as seen on the right side of Figure 2. It describes an exercise about syllables that contains 3 levels namely syllables with format of CVC, VCVC, and CVCVC (V=vowel, $\mathrm{C}=$ consonant). This concept of leveling can be implemented in other language as well. 


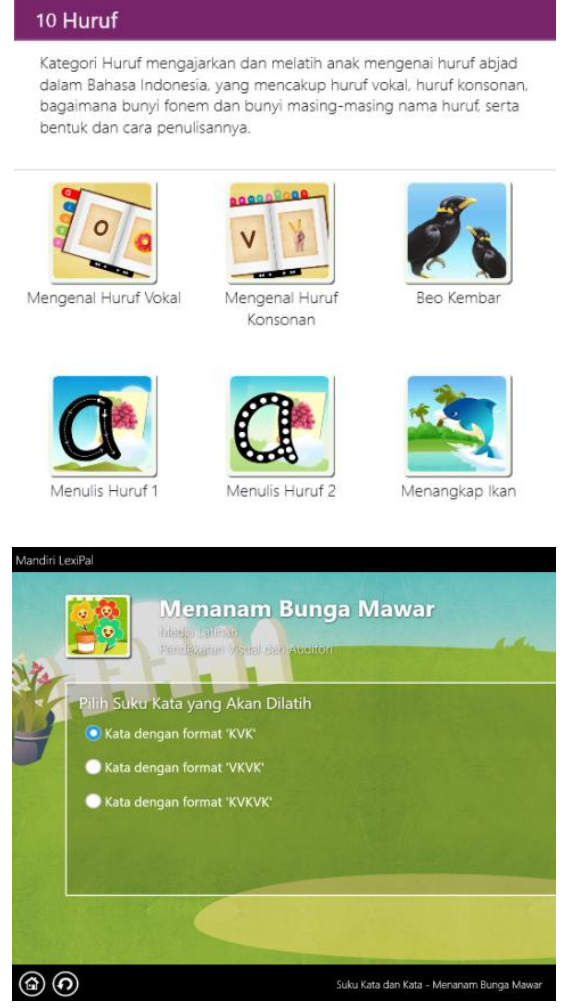

Fig 2: Picture on the top shows that a category consists of several media sorted from the easiest one to the most difficult one. Picture on the below depicts an example of list of levels in a learning media that showing difficulty level as well.

Figure 3 demonstrates the example of LexiPal's gamified learning. This learning media is named "A chicken is looking for his corn". This media incorporates some game elements that is story, clear goal, level, feedback, and points. The description about the story, goal, and level (Stage 1) is presented on description page, while the points and feedback (part of Stage 2) are given exactly after an event happens in main application page. The detail is explained as follows:

Story: Once upon a time, in a yard, there is a happy chicken named "Chicky". Chicky loves to walk around in the yard to find corn for his meal. He loves corn so bad. One day, Chicky finds out a place that could supply him many corns. However, he has to find the correct route to reach the place. In order to find the right path, he should choose all of requested letters. Can you help Chicky find his food by choosing the correct letter as instructed?

Clear goal: Choose the correct letter based on the instruction in order to move Chicky to their target corn.

Levels: The easiest level contains very different letters while the hardest level contains very similar letters. There are 5 levels for each game.

Feedback: If dyslexic choose correct letter, the letter box will turn into green colour and a correct sound effect will be played. Otherwise, the letter box will turn into red colour and a false (but not intimidating) sound effect will be played.

Points: When dyslexic succeed on choosing all of the correct letters, the application gives 1 star as a point and a reward.

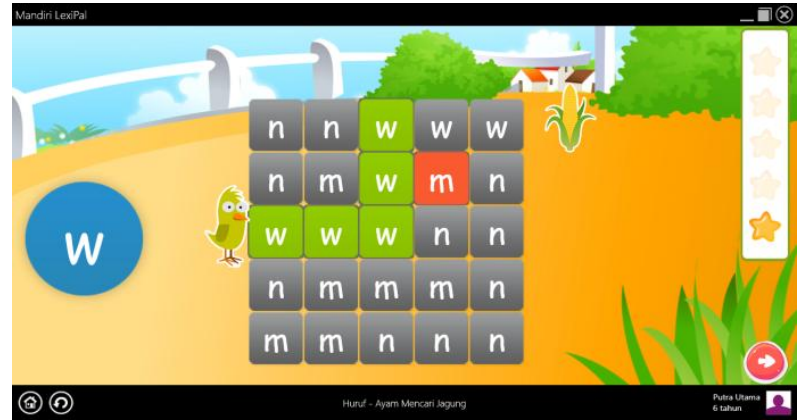

Fig 3: Example of gamified learning that incorporates the following game elements: story, clear goal, feedback, and points.

Figure 4 depicts an application page that incorporates all of game elements in Stage 2, namely point, rewards, and feedback. Everytime dyslexic finish one round of game, a pop up window is appeared to show the score, the reward, and the predicate they got. If they got score 4-5, they will get a golden cup and an "excellent" predicate ("hebat" in Indonesian) through text and voice feedback. If it is 3 , the predicate will be "good" while if it is below 3, the application give voice feedback to encourage them to try it again.

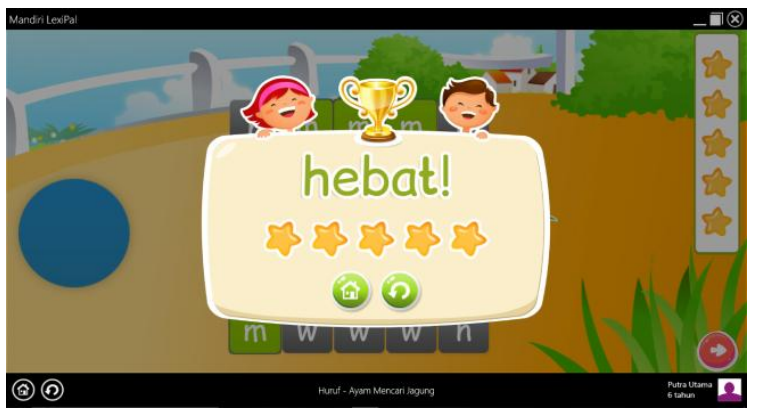

Fig 4: The application shows the reward when user finish one round of game

Figure 5 shows example of badges (Stage 3). The figure on the top indicates the badges that dyslexic will get when they finish specific subject. For instances, the badge on the top left figure will be given after dyslexic finish learning all letters, while the badge on the top right figure will be granted after dyslexic master certain syllables. The picture on the below depicts the example of a certificate that can be printed after dyslexic got a badge. This certificate can be printed in a paper thus the parent/teacher can stick it on their wall to motivate them to achieve more.

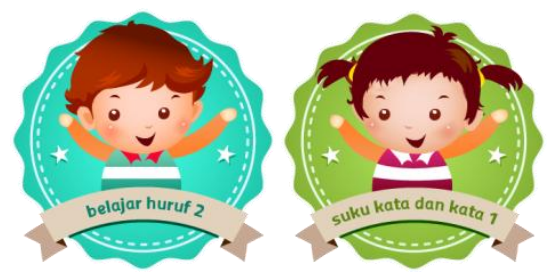




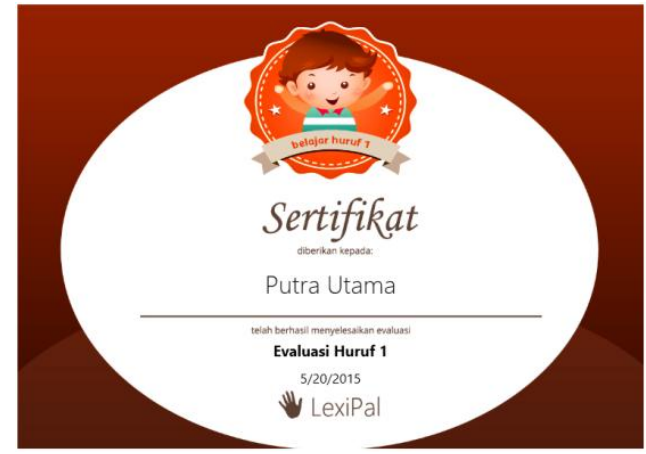

Fig 5: The top figure shows the example of badges while the figure on the bottom shows an example of certificate

\section{EVALUATION}

\subsection{Evaluation Method}

Evaluation of LexiPal was conducted in headquarter of Dyslexia Association of Indonesia, in Bandung city. LexiPal was tested to 40 dyslexic children with the age of 5-8 years old. The evaluation was divided into 2 stages, i.e. qualitative stage and quantitative stage. In qualitative stage, observation was chosen to evaluate the first psychological outcomes, which is engagement. The observation was conducted to observe engagement of dyslexic children in learning a subject with and without LexiPal application. When using LexiPal, every dyslexic children tried the application for each category one by one for about 45 minutes. At this time, the observation is running simultaneously with the quantitative stages. Basically, the quantitative stage was conducted based on questionnaire. However, because of inability of most of dyslexic children to read well in the age of 5-8 years old, the question was delivered verbally. The answered was restricted into 2 options, namely agree or disagree, in order to make it easier for them. Moreover, the question was conveyed in understandable language for 5-8 years old dyslexic.

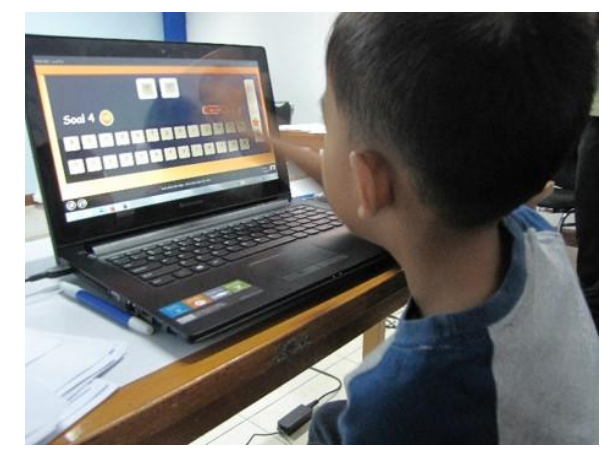

Fig 6: Evaluation of the application to dyslexic children

On quantitative stage, dyslexic was inquired in regard to 2 things after they have finished each category. The first question is: whether they feel happy when using the application. This question is aimed to confirm the enjoyment outcomes. The second question is: whether they desire to use the application again in the near future. This question confirms motivation outcomes as motivation refers to engage to take action because of external reward. Thus, this question want to make sure whether the gamification elements contributes in generating motivation or not. Figure 6 depicts the evaluation process of the application.

\subsection{Result and Discussion}

Engagement is indicated with participation and interest [25]. These two indicators are used to determine whether dyslexic engages with the learning material. Based on observation, all of dyslexic children are willing to learn the presented subject using the application. All of them eager to participate in the evaluation. Some of them even want to continue to use the application eventhough the evaluation was already done. However, not all of them (only 92.5\%) can keep their interest throughout the session. Three of dyslexic (7.5\%) want to stop using the application before the session was ended, eventhough the teachers manage to keep them continuing the session and finishing all of evaluation steps. However, the reason behind it are various and includes external factors. For instances, they want to stop because they are tired, hungry, or want to eat. This result needs more investigation in the future.

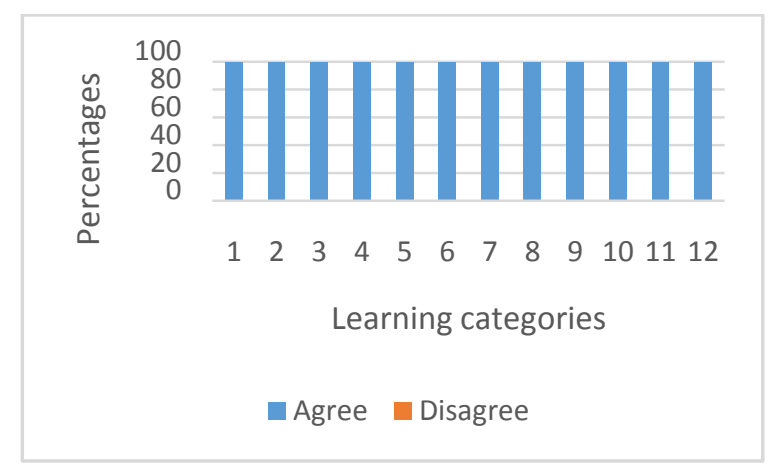

Fig 7: The evaluation result of the application toward enjoyment question.

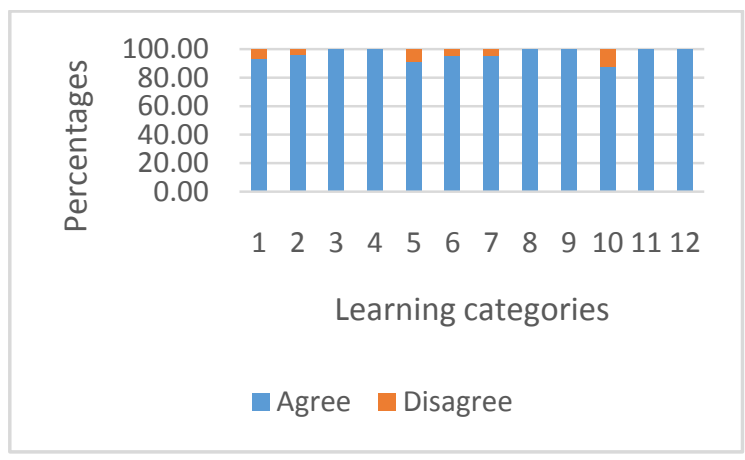

Fig 8: The evaluation result of the application toward "eagerness to play again" question

The result of quantitative stage can be seen in Figure 7 dan 8 . Figure 7 describes the evaluation result of the first question. It can be seen from the chart that for all of learning categories, all of dyslexic children $(100 \%)$ feel happy and enjoy when playing the application. This indicates that the enjoyment factor is achieved by incorporating gamification. Figure 8 depicts the evaluation result of the second question. The chart shows that some dyslexic children do not want to play the application again for some categories such as shape and pattern, direction, or alphabet. It may due to the difficulty level of some learning media that are too hard for them. Moreover, as the age of dyslexic children on this evaluation ranges from 5-8 years old, there will be some of them that too early to learn alphabet or syllables, thus make them bored and have no eager to learn again in the future. Hence, the implementation of difficulty level needs to be improved again in further research. Finally, for the second question, the average of $96.64 \%$ of dyslexic children agree to use the 
application again. It shows their eagerness to play it again in the near future.

The result of the evaluation indicates short-term psychological outcomes after dyslexic use the application for short period of times (45 minutes). This research is not exploring the longterm outcome yet. For further investigation, the evaluation should be conducted in longer period of time, for example 3 months, hence the effectivity of the gamification approach toward long-term motivation can be discovered. Furthermore, the effect of gamification can be studied deeply by providing much more questions to dyslexic children. However, the question should be delivered step by step on different timeframe thus dyslexic will not feel bored and eager to answer the questions.

\section{CONCLUSION}

This research design gamification learning model for dyslexic children, termed LexiPal, by incorporating seven gamification elements, namely story/theme, clear goals, levels, points, rewards, feedback, and achievements/badges. These game elements intend to yield desired psychological outcomes when dyslexic uses the application, including engagement, enjoyment, and motivation. The application implement this model in a software application using Windows Presentation Foundation Technology. The application was evaluated to 40 dyslexic children using two steps, qualitative step and quantitative step. Based on the observation when dyslexic using the application, it shows that gamification increases their interest in using the application. Most of dyslexic were eager to participate in the evaluation process until it was ended, thus the effect of gamification on improving dyslexic engagement is confirmed. On quantitative step, $100 \%$ of dyslexic enjoy playing the application while only $96.64 \%$ of them who want to play it again. It indicates that gamification can improve enjoyment and motivation of the children eventhough some improvement in difficulty level is needed. However, this result is considered as a short-term effect, which is the effect of gamification when and after dyslexic children use the application in short duration (45 minutes). Long-term effect of gamification needs to be investigated in the next research. More comprehensive Q\&A is required as well to deeply analyze the evaluation result.

\section{ACKNOWLEDGMENTS}

Thanks to dr. Purboyo Solek Sp.A(K), dr. Kristiantini Dewi, Sp.A, and all team members of Dyslexia Association of Indonesia for their noble guidances in conducting this research. This research is supported and funded by Mandiri Bank as Corporate Social Responsibility (CSR) programme. The final resut and the detail about this work can be seen at www.lexipalindonesia.com.

\section{REFERENCES}

[1] IDA, "Fact Sheets On Dyslexia and Related LanguageBased Learning Disabilities," The International Dyslexia Association, 2012. [Online]. Available: http://www.interdys.org/FactSheets.htm.

[2] T. Wood, Overcoming Dyslexia for Dummies. Indiana: Wiley Publishing, Inc., 2006.

[3] F. R. Vellutino, J. M. Fletcher, M. J. Snowling, and D. M. Scanlon, "Specific reading disability (dyslexia): what have we learned in the past four decades?," Journal of child psychology and psychiatry, and allied disciplines, vol. 45, no. 1, pp. 2-40, Jan. 2004.

[4] S. E. Shaywitz and B. A. Shaywitz, "The science of reading and dyslexia," Journal of American Association for Pediatric Ophthalmology and Strabismus, vol. 7, no. 3, pp. 158-166, Jun. 2003.

[5] D. Gooch, A. Vasalou, and L. Benton, "Exploring the use of a Gamification Platform to Support Students with Dyslexia," in 6th International Conference on Information, Intelligence, Systems and Applications, 2015.

[6] D. a. Zisimopoulos and E. P. Galanaki, "Academic Intrinsic Motivation and Perceived Academic Competence in Greek Elementary Students with and without Learning Disabilities," Learning Disabilities Research \& Practice, vol. 24, no. 1, pp. 33-43, 2009.

[7] J. Hamari, J. Koivisto, and H. Sarsa, "Does Gamification Work? -- A Literature Review of Empirical Studies on Gamification," in 47th Hawaii International Conference on System Sciences, 2014, pp. 3025-3034.

[8] A. Domínguez, J. Saenz-de-Navarrete, L. de-Marcos, L. Fernández-Sanz, C. Pagés, and J.-J. Martínez-Herráiz, "Gamifying learning experiences: Practical implications and outcomes," Computers \& Education, vol. 63, pp. 380-392, Apr. 2013.

[9] B. W. Betts, J. Bal, and A. W. Betts, "Gamification as a tool for increasing the depth of student understanding using a collaborative e-learning environment," International Journal of Continuing Engineering Education and Life-Long Learning, vol. 23, no. 3/4, pp. 213-228, 2013.

[10] S. Deterding, D. Dixon, R. Khaled, and L. Nacke, "From Game Design Elements to Gamefulness: Defining "Gamification," in 15th International Academic MindTrek Conference: Envisioning Future Media Environments, 2011, pp. 9-15.

[11] J. Ohene-Djan and R. Begum, "Multisensory Games for Dyslexic Children," in The 8th IEEE International Conference on Advanced Learning Technologies, 2008.

[12] I. Smythe and S. Giulivi, "A Model of Dyslexia-Friendly Language-Learning Computer Game Development," in 4th International Conference on ICT for Language Learning, 2010.

[13] L. Rello, C. Bayarri, and A. Gorriz, "What is Wrong with this Word? Dyseggxia: a Game for Children with Dyslexia Categories and Subject Descriptors," in 14th International ACM SIGACCESS Conference on Computers and Accessibility, 2012, pp. 6-7.

[14] P. A. Di Tore, S. Di Tore, L. A. Ludovico, and G. R. Mangione, "MADRIGALE: A Multimedia Application for Dyslexia and Reading Improvement GAmifying Learning Experience," in 2014 International Conference on Intelligent Networking and Collaborative Systems, 2014, pp. 486-491.

[15] F. Malekian and B. Askari, "Investigating the Effect of Multi-sensory Games on Decrease of Male Students' Dyslexia (Based on Goodman Theory) Specified for Elementary School Second Grade in Aligudarz City," Procedia - Social and Behavioral Sciences, vol. 82, pp. 796-802, Jul. 2013.

[16] S. M. Daud and H. Abas, “Dyslexia Baca' Mobile App The Learning Ecosystem for Dyslexic Children," in International Conference on Advanced Computer 
Science Applications and Technologies, 2013, pp. 412416.

[17] R. Skiada, E. Soroniati, A. Gardeli, and D. Zissis, "EasyLexia: A Mobile Application for Children with Learning Difficulties," Procedia Computer Science, vol. 27, no. Dsai 2013, pp. 218-228, 2014.

[18] S. Purkayastha, N. Nehete, and J. Purkayastha, "Dyscover - An Orton-Gillingham Approach Inspired Multi-sensory learning application for Dyslexic Children," in World Congress on Information and Communication Technologies, 2012, pp. 685-690.

[19] S. Z. Ahmad, N. N. A. A. N. Ludin, H. M. Ekhsan, A. F. Rosmani, and M. H. Ismail, "Bijak Membaca - Applying Phonic Reading Technique and Multisensory Approach with Interactive Multimedia for Dyslexia Children," in IEEE Colloquium on Humanities, Science \& Engineering Research, 2012, no. Chuser, pp. 554-559.

[20] J. Khakhar and S. Madhvanath, "JollyMate: Assistive Technology for Young Children with Dyslexia," in 12th International Conference on Frontiers in Handwriting Recognition, 2010, pp. 576-580.

[21] A. Marczewski, Gamification: A Simple Introduction. Customer Loyalty, 2013.

[22] S. Deterding, "Gamification: designing for motivation," Interactions, vol. 19, pp. 14-17, 2012.

[23] K. Huotari and J. Hamari, "Defining Gamification - A Service Marketing Perspective," in Proceedings of the 15th International Academic MindTrek Conference: Envisioning Future Media Environments, 2012, pp. 1722

[24] J. Hamari, J. Koivisto, and T. Pakkanen, "Do Persuasive Technologies Persuade?-A Review of Empirical Studies," Persuasive Technology, pp. 118-136, 2014.

[25] J. J. Appleton, S. L. Christenson, and M. J. Furlong, "School Engagement with School: Critical Conceptual and Methodological Issues of the Construct," Psychology in the Schools, vol. 45, no. 5, 2008.

[26] L. Abeysekera and P. Dawson, "Motivation and cognitive load in the flipped classroom: definition, rationale and a call for research," Higher Education Research \& Development, vol. 34, no. 1, pp. 1-14, 2015.

[27] M. Y. Yi and Y. Hwang, "Predicting the use of webbased information systems: self-efficacy, enjoyment, learning goal orientation, and the technology acceptance model," International Journal of Human-Computer Studies, vol. 59, no. 4, pp. 431-449, 2003.

[28] M. R. U. Saputra and K. A. Nugroho, “'Learn-to-read' Application for Remediation of Dyslexic Children Based on Multisensory Approach," in 4th International Conference on Instrumentation, Communication, Information Technology, and Biomedical Engineering, 2015.

[29] A. Nathan and L. Daniel, Windows Presentation Foundation Unleashed. Sams Publishing, 2007. 